\title{
Prevalence of sexually transmitted diseases in pregnant women in Ikot Ekpene, a rural community in Akwa Ibom State, Nigeria
}

\author{
Etim Inyang Ekanem ${ }^{1 *}$, Mbabel Ekott ${ }^{1}$, Atim Edet Udo ${ }^{1}$, Efiok Eyo Efiok ${ }^{1}$, Attah Inyang-Out ${ }^{2}$ \\ ${ }^{1}$ Department of Obstetrics \& Gynecology, College of Medical Sciences, University of Calabar, Calabar, Nigeria \\ ${ }^{2}$ Department of Microbiology, General Hospital, Ikot Ekpene, Nigeria \\ Email: ${ }^{2}$ ekanmetim@yahoo.com
}

Received 2 November 2011; revised 6 December 2011; accepted 24 December 2011

\begin{abstract}
Background: Sexually transmitted diseases are associated with adverse consequences in pregnancy and its outcome. However, early detections and effective treatments would prevent the associated complications. Objectives: The main aims of this study are to determine the prevalence of common sexually transmitted diseases and to assess the socio-demographic profile of the women. Subjects and Methods: Samples were collected from 560 pregnant women at the first antenatal visit in the hospital after they were counseled and informed consent obtained. Pre-tested questionnaires were used to assess their socio-economic and demographic characteristics. The samples were subjected to the relevant laboratory tests and analysis. Results: Out of the $\mathbf{5 6 2}$ pregnant women examined, $250(44.5 \%)$ were infected with various etiologic agents. Genital candidasis was the highest infection encountered in $119(21.1 \%)$ women followed by Bacterial vaginosis in 38 (6.8\%) and Chalamydiae in 35 (6.2\%). Others infections included Hepatitis 8 (1.4\%); Trichomonasis 29 (5.2\%); Human immunodeficiency virus infection 12 (2.1\%), Syphilis 7 (1.2\%) and 2 Gonococcal infections respectively. The mean parity of the women with infection was $3 \pm 1.4$ and majority was asymptomatic $(\mathbf{5 7 . 1 \% )}$. The prevalence rate of infection was inversely associated with increasing maternal age and advanced formal educational status. The mean gestational age was 19 weeks \pm 4.2 and appeared highest with earlier gestational age. Conclusion: There is high prevalence of sexually transmitted diseases among our pregnant women with most of them being asymptomatic. Screening for and prophylactic treatment of the common treatable infection at booking may reduce the incidence of adverse maternal and perinatal outcome associated with these infections.
\end{abstract}

\footnotetext{
"Corresponding author.
}

Keywords: Pregnant Women; STDs; Diagnosis; Maternal Morbidity

\section{INTRODUCTION}

More than 25 infectious organisms are transmitted primarily through sexual contacts but the common ones includes bacterial vaginosis, herpes simplex, Chlamydia, trichomoniasis, gonococcal, Hepatitis B virus, HIV and syphilitic infections [1,2]. This age long infectious diseases have been recognized as major public and reproductive health challenges worldwide. The impact of this group of infections on the scarce resources of most individuals, family and developing nations are enormous and often under estimated [3]. Even though pregnant women are regarded as low risk group for acquiring infections the effect and consequences are of more serious compared to the none pregnant counterpart [4].

STDs in non pregnant women have tremendous adverse consequences on the health and economic life the patients that can lead to pains, organs damage, serious disabilities such as blindness, deafness, insanity, paralysis and even mortality [5,6]. These consequences are more severe in pregnant women and therefore, early detection and treatment avert these problems. The impact of these infections on the obstetric outcome and management are well known [1,2,5]. STDs have been associated with conditions such as spontaneous miscarriages, stillbirth, prematurity, low birth weight, preterm labour, premature rupture of fetal membranes and postpartum endometritis. Other long term morbidities such as cervical cancers, chronic hepatitis, and chronic pelvic infection are also observed in women with these infections in pregnancy [7].

STDs can be transmitted from a pregnant mother to the baby, during antepartum, intrapartum and postpartum periods. For example, some STDs like syphilis can cross the placenta and infect the baby in-utero [7] while others like gonorrhea, chalamydia, hepatitis B viruses and Geni- 
tal herpes can be transmitted to the baby during delivery through the birth canal $[8,9]$. Some babies can acquire HIV during the postpartum period through breast feeding [10].

It is estimated that the number of pregnant women with STDS is increasing by about 250 million a year in the developed countries [11] and double that number in the developing countries [12]. In spite of the sequalae of these infections, there is inadequate statistical data on the prevalence of STDs in pregnant women in Ikot Ekpene, Akwa Ibom State. This study therefore conducted in this with the main objectives of documenting the prevalence of these of common STDs in pregnancy among women this rural community and to assess the socio-demographic profiles of the women with these STDs.

\section{MATERIALS AND METHODS}

This is a cross sectional observational study conducted over 7 month period from $1^{\text {st }}$ June to $31^{\text {st }}$ December, 2010.

The sample size was estimated by previous study done in the region to be 545 for the population with a confidence interval of $95 \%$ and precision of $\pm 5 \%$ but samples were collected from 562 women.

\subsection{Study Location}

The study location was General Hospital Ikot Ekpene Akwa Ibom State in Nigeria. Ikot Ekpene is a rural community in Akwa Ibom State which is located in the Niger Delta region of Nigeria. It has population of 1.3 million people who are mainly subsistent farmers, petty traders, civil servants and housewives. The General Hospital is the only secondary level health care referral center in the area. The antenatal clinic is conducted twice every week (one booking and one follow up clinic). The hospital has an estimated 500 antenatal women per month and an annual delivery of 1200 women.

\subsection{Methods}

After obtaining the relevant ethical approval from the authority, the study was carried out in the registration first antenatal clinic visit. The women were adequately counseled and then recruited into the study after unwritten consent was obtained. Those who refused to participate in the study were excluded but were assured of receiving normal and adequate services in the clinic. Other excluded were those on antibiotic and steroid therapies as well as diabetic mellitus patients. Pre-tested semistructured questionnaires developed during a pilot study were administered to the women to obtained relevant demographic and reproductive information such as age, social status, parity, menstrual history.
Normal antenatal history and thorough physical examination were then conducted to detect clinical signs of infections.

\subsection{Collection of Sample}

Representative samples were the collected and process in standard manner as follows.

\section{High Vaginal and Endocervical Swabs}

With sterile gloves the vaginal fornices and the cervix were adequately exposed with sterile bivalve speculum. Separate swabs were then taken from the posterior fornix and the endocervix with sterile swab sticks. The sample from the vagina was smeared on 2 separate glass slides. Normal saline and potassium hydroxide was put on each of the slides respectively. The sample from the cervix was put in Stuart transport medium (STM) [Oxoid Ltd, UK] and transported to laboratory immediately for processing. Venous blood samples were also aseptically collected from the participants in sterile container for processing. HIV testing was unlinked, anonymous, therefore informed consent and counseling was not necessary [13-15].

\subsection{Processing of Samples}

All samples were processed by the same group of staff under the direct supervision by one of authors to ensure that compliance to standard procedure and remove observer errors.

\subsubsection{Direct Examination}

Wet mounts of all swab samples were made in sterile normal saline on clean slides and examined under the low power $(10 \times)$ and high power $(40 \times)$ magnifications for typical yeast cells with hyphae or pseudohyphae and Trichomonas vaginalis. Gram stain was carried out on both ECS and HVS and examined with 100× objective under oil immersion for Gram negative diplococci and clue cells. Endocervical swab specimens were inoculated into blood agar and Thayer Martin agar (prepared as described by [16]) while HVS specimens were inoculated into blood gar and sabouraud dextrose agar (SDA) [Biotec, Ipswich, UK].

\subsubsection{Identification of Isolates}

Yeast isolates were screened for germ tube production in serum broth. Candida albicans were identified on the basis of the following features: thick-walled oval yeast cells with pseudomycelium and germ tube formation in human serum at $37^{\circ} \mathrm{C}$. Germ tube negative species were regarded simply as yeast species.

Gardnerella vaginalis was identified by a combination 
of wet preparation appearance, Gram staining reaction and the $\mathrm{pH}$ of the discharge. The wet preparation showed abundance of "clue cells" [squamous epithelial cells whose surfaces were smothered with masses of micro-organisms], the $\mathrm{pH}$ of the saline preparation was found to vary between 5.0 - 5.6 [i.e. higher than normal $\mathrm{pH}$ of 3.0 - 4.5] when measured with a $\mathrm{pH}$ indicator paper (BDH, UK) and in a Gram stain of positive cases, the normal lactobacilli flora was almost or completely replaced with masses of Gram variable organisms. The specimens that were positive for pathogens were cultured and antibacterial sensitivity determined.

\subsubsection{Antibodies Serological Tests}

Separated serum from blood samples were dispensed into two $3 \mathrm{ml}$ volumes sterile plastic containers and used within 2 days for screening tests of HIV, syphilis, Hepatitis B surface Antigen and Chlamydia. Others were frozen for confirmatory tests.

HIV antibody assay was carried out with Determine HIV 1 \& 2 rapid test strips (Abbott laboratories-USA) and HIV 1 \& 2 Stat-Pat assay (Chembio diagnosticsUSA) methods according to the standard national HIV screening in Nigeria $[17,18]$. These tests are qualitative membrane-based immuno assay techniques. All seropositive samples were further confirmed and differentiated into HIV 1 \& 2 using immumo comb HIV 1 \& 2 Biospots (Organics, Israel).

Syphilis antibodies were estimated by using syphilis ultra-rapid test strips (Clinotech Diagnostics-Canada). All reactive syphilis samples (containing Treponema Pallidum antibodies) were further tested and confirmed with TPHA (Teco Diagnostics-USA). Hepatitis B surface antigen test was done using Hepatitis B surface antigen test strips $\left(\right.$ Acon $^{\mathrm{R}}$ laboratories-USA). Chlamydia antibodies was tested using immunocomb Chlamydia Bivalent IgG test kit (Orgenics Medical Group-France), a semi quantitative and differential indirect solid phase enzyme immuno assay.
All the patients with infections were treated appropriately using national standard protocol. HIV seropositive women were referred for enrolment in the hospital prevention of maternal to child transmission programs and treated accordingly.

The data collected was analyzed using SPSS Version 11 computer soft ware and result presented with frequency table. Test of significance between variables were done and significance put at $\mathrm{P}=<0.05$.

\section{RESULTS}

Out of 562 pregnant antenatal women tested, 250 (44.5\%) were infected with various etiologic agents. The prevalence of pathogens detected among women is presented in Table 1. Candida albicans had the highest percentage of infection occurrence 121 (21.5\%), followed by HIV 38 (6.8\%) and Chlamydia species, 35 (6.2\%). Others were Trichomonas vaginalis 29 (5.2\%); Gardnerella vaginalis (Bacterial vaginosis) 12 (2.1\%); Hepatitis B Surface Antigen (HBsAg); 8 (1.4\%) and Treponema pallidum (syphilis) 7 (1.2\%). Two cases of Nessaeria gonorrhoea were indentified in the study. Only HIV-1 was detected in all seropositive HIV samples.

The results of the confirmatory test for Treponema pallidum performed on all strip reactive samples shows the sero-prevalence of the infection among the pregnant women. Only serum samples that gave agglutination at dilution titers of 160 and above were considered significantly positive [19]. Out of the seven (7) reactive samples with strip test, five (5) were found to be TPHA positive.

Table 2 shows the age specific distribution of infections among pregnant women in the study. Pregnant women in the age group of 15 - 19 years had a higher infection distribution rate 58(74.3\%), followed by 20 24 years $78(70.2 \%)$ with all of them testing positive to one or more pathogens except Neisseria gonorrhoeae. There was a high significant association between age groups and infection acquisition $(\mathrm{P}<0.05)$.

Table 1. Prevalence sexually transmitted diseases among pregnant women in the study.

\begin{tabular}{lcc}
\hline Pathogens & No. detected & Frequency (\%) \\
\hline Genital candidiasis & 119 & 21.1 \\
Trichomonasis & 29 & 5.2 \\
Bacterial vaginosis & 12 & 2.1 \\
Syphilis & 7 & 1.2 \\
Hepatitis B infection & 8 & 1.4 \\
Human immunodeficiency virus infection & 38 & 6.8 \\
Neisseria gonorrhea & 2 & 0.3 \\
Ghlamydia infection & 35 & 6.2 \\
Total & $\mathbf{2 5 0}$ & $\mathbf{4 4 . 5}$ \\
\hline
\end{tabular}


Table 3 shows marital status of women with the infections. Divorcees and widows appear to be having the highest infection rate of $4(66.7 \%)$ and $2(66.7 \%)$ respectively but the total number of women tested among them was few. Infection occurrence was less in single 55 (41.7\%) and married 189 (44.9\%) pregnant women in the study. Statistical analysis showed that marital status was not a significant factor in infection occurrence $(\mathrm{P}>0.05)$.
Infection was more during the first trimester of pregnancy in this study with a prevalence rate of 73 (967.6\%) followed by third trimester $43(46.7 \%)$ and less in the second trimester 134 (37.0\%) (Table 4). The average gestational age among those with infections was 19 weeks \pm 4.2. Statistical analysis of the relationship between these trimesters and infection prevalence was significant $(\mathrm{P}<0.05)$.

Table 2. Age specific distribution of infections among pregnant women in the study.

\begin{tabular}{|c|c|c|c|c|c|c|c|c|c|c|}
\hline \multirow{2}{*}{$\begin{array}{l}\text { Age } \\
\text { (Yrs) }\end{array}$} & \multirow{2}{*}{$\begin{array}{l}\text { No. } \\
\text { Tested }\end{array}$} & \multirow{2}{*}{$\begin{array}{l}\text { No } \\
\text { (\%) }\end{array}$} & \multicolumn{8}{|c|}{ No. (\%) Positive for actual pathogens detected } \\
\hline & & & $\mathrm{Ng}$ & Ca.alb & T.V & G.V & T.P & HBsAg & HIV & Ch.sp \\
\hline $15-19$ & 78 & $58(74.3)$ & 0 & $30(38.5)$ & $8(10.3)$ & $4(5.1)$ & $1(3.1)$ & - & $5(6.4)$ & $10(12.8)$ \\
\hline $20-24$ & 111 & $78(70.2)$ & 1 & 35 (31.5) & $12(10.8)$ & $3(2.7)$ & $2(1.8)$ & $2(1.8)$ & $16(14.4)$ & $8(7.2)$ \\
\hline $25-29$ & 160 & $54(33.8)$ & 1 & $25(15.6)$ & $4(2.5)$ & $3(1.9)$ & $2(1.2)$ & $2(1.3)$ & $10(6.3)$ & $8(5.0)$ \\
\hline $30-34$ & 135 & $38(28.1)$ & 0 & $21(15.6)$ & $4(3.0)$ & $2(1.5)$ & $1(0.7)$ & $1(0.7)$ & $3(2.2)$ & $6(4.4)$ \\
\hline $35-39$ & 58 & 17 (29.3) & 0 & $8(13.8)$ & $1(1.7)$ & 0 & $1(1.7)$ & $1(1.7)$ & $2(3.4)$ & $3(5.2)$ \\
\hline $40-49$ & 20 & $5(25.0)$ & 0 & $2(10.0)$ & 0 & 0 & 0 & 0 & $2(10.0)$ & 0 \\
\hline Total & 562 & $250(44.5)$ & 2 & $121(21.5)$ & $29(5.2)$ & $12(2.1)$ & $7(1.2)$ & $8(1.4)$ & $38(6.8)$ & $35(6.2)$ \\
\hline
\end{tabular}

$\mathrm{Ng}=$ Neisseria gonorrhoeae; HBsAg = Hepatitis B surface antigen; Ca.sp = Candida albicans; HIV = Human Immunodeficiency Virus; T.V = Gardnerella vaginalis; Ch.sp = Chlamydia species.

Table 3. Occurrence of infection by marital status of pregnant women.

\begin{tabular}{|c|c|c|c|c|c|c|c|c|c|c|}
\hline \multirow{2}{*}{ Marital Status } & \multirow{2}{*}{$\begin{array}{l}\text { No. } \\
\text { Tested }\end{array}$} & \multirow{2}{*}{$\begin{array}{l}\text { No. (\%) } \\
\text { Positive }\end{array}$} & \multicolumn{8}{|c|}{ No. (\%) Positive for pregnant women } \\
\hline & & & $\mathrm{Ng}$ & Ca.alb & T.V & G.V & T.P & HBsAg & HIV & Ch.sp \\
\hline Single & 132 & $55(41.7)$ & 1 & $32(3.8)$ & $7(5.3)$ & $3(2.3)$ & $1(0.8)$ & $1(8.0)$ & $6(4.5)$ & $2(1.5)$ \\
\hline Married & 421 & 189 (44.9) & 1 & $83(19.7)$ & $22(5.2)$ & $9(2.1)$ & $6(1.4)$ & $6(1.4)$ & $29(6.9)$ & $33(7.8)$ \\
\hline Divorced/Seperated & 6 & $4(66.7)$ & 0 & $2(33.3)$ & 0 & 0 & 0 & 0 & $2(33.3)$ & 0 \\
\hline Widowed & 3 & $2(66.7)$ & 0 & $1(33.3)$ & 0 & 0 & 0 & 0 & $1(33.3)$ & 0 \\
\hline Total & 562 & $250(44.5)$ & 2 & 121 (21.5) & $29(5.2)$ & $12(2.1)$ & $7(1.2)$ & $8(1.4)$ & $38(6.8)$ & $35(6.2)$ \\
\hline
\end{tabular}

$\mathrm{Ng}$ = Neisseria gonorrhoeae; HBsAg = Hepatitis B surface antigen; Ca.sp = Candida albicans; HIV = Human Immunodeficiency Virus; T.V = Gardnerella vaginalis; Ch.sp = Chlamydia species; T.P = Treponema pallidum; - = Denotes that no pathogen was detected.

Table 4. Prevalence of infection by trimester of pregnancy.

\begin{tabular}{|c|c|c|c|c|c|c|c|c|c|c|}
\hline \multirow{2}{*}{$\begin{array}{l}\text { Trimester } \\
\text { (weeks) }\end{array}$} & \multirow{2}{*}{$\begin{array}{l}\text { No. } \\
\text { Tested }\end{array}$} & \multirow{2}{*}{$\begin{array}{l}\text { No. (\%) } \\
\text { positive }\end{array}$} & \multicolumn{8}{|c|}{ No. (\%) Positive for pathogens } \\
\hline & & & $\mathrm{Ng}$ & Ca.alb & T.V & G.V & T.P & HBsAg & HIV & Ch.sp \\
\hline First (1 - 13) & 108 & $73(67.6)$ & 2 & $38(35.2)$ & $9(8.3)$ & $3(2.8)$ & $1(1.9)$ & $1(0.9)$ & $11(10.2)$ & $9(8.3)$ \\
\hline Second (14 - 28) & 362 & $134(37.0)$ & 0 & $60(16.6)$ & $16(4.4)$ & $6(1.7)$ & $4(1.1)$ & $5(1.4)$ & $23(6.4)$ & $20(5.5)$ \\
\hline Third (29 - 40) & 92 & $43(46.7)$ & 0 & $23(25.0)$ & $4(4.3)$ & $3(3.3)$ & $1(1.1)$ & $2(2.2)$ & $4(4.3)$ & $6(6.5)$ \\
\hline Total & 562 & $250(44.5)$ & 2 & $121(25.1)$ & $29(2.5)$ & $12(2.1)$ & $7(1.2)$ & $8(1.4)$ & $38(6.8)$ & $35(6.2)$ \\
\hline
\end{tabular}

$\mathrm{Ng}$ = Neisseria gonorrhoeae; HBsAg = Hepatitis B surface antigen; Ca.sp = Candida albicans; HIV = Human Immunodeficiency Virus; T.V = Gardnerella vaginalis; Ch.sp = Chlamydia species; T.P = Treponema pallidum; - = Denotes that no pathogen was detected. 
Assessment of educational level of the women with infections shows that those that were not educated at any level had the highest infection occurrence 3 (100\%) followed by women with Quranic education 5 (83.3\%). Overall, infection rates were higher in women with none and low educational background. Educational status was a significant factor in infection acquisition $(\mathrm{P}<0.05)$.

Infection was commoner in women of low parity though it did not show statistically significant relationship with primigravida having the highest rate of 52.9\%.

Clinical presentations shows infected women were asymptomatic in 148 (57.1\%), vulvo-vaginal discharge in 57 (22.0\%), dysparuenia in 26 (10.0\%) lower abdominal pains in 15 (5.8\%) with urinary tract symptoms and genital soreness being less common.

The occurrence of infection among the women by occupation in Table 5 shows that housewives recorded the lowest rate of infection 68 (31.5\%), followed by civil servants 48 (45.7\%). Unemployed women and students recorded the highest occurrence rate of 59 (66.3\%) and 14 (50.0\%) respectively. Occupation was significantly associated with infection occurrence ( $\mathrm{P}<0.05 \%)$.

\section{DISCUSSIONS}

The results of this study have demonstrated the endemicity and occurrence of significant levels of sexually transmitted infections in pregnant women in Ikot Ekpene, Akwa Ibom State, Nigeria. Pregnant women have been accepted as a low risk group in terms of STD transmission; prevalence level of these infections in them are employed globally as a yardstick for evaluating the trend of such infections within the general population at low risk of getting infected [14]. A study of the prevalence of STDs in pregnant women is an approximation of the prevalence of these infections in their male counterparts and sexually active non pregnant women [14].

The commonest organism encountered in this study was Candida albicans 121 (921.5\%). This finding is comparable with previous studies on STDs amongst pregnant and non-pregnant women in Illorin [20], Ife [21] and Jos, Nigeria [22]. This may be explained by the fact that pregnancy appears to predispose to genital candidiasis and not all infections were sexually transmitted. Though serious adverse pregnancy outcome is not common treatment is necessary to relieve the symptoms of this infection.

The prevalence rate of $6.8 \%$ recorded for HIV in this study compares favorably with that of the Federal Ministry of Health [18] Sentinel Study on HIV in pregnant women in Nigeria where a seroprevalence rate of $6.1 \%$ was recorded for Akwa Ibom State. Elsewhere in Nigeria higher seroprevalence rate among pregnant women have been reported, for instance, $13.0 \%$ in Makurdi (Benue State) and $10.0 \%$ in Saminka (Kaduna State) [18].

Qualitative TPHA test of the 7 reactive strip samples, found significant treponemal antibodies in 5 of them, absence of significant treponemal antibodies in 2 of these samples tested with TPHA may suggest a non syphilitic regain antibody production or cross reaction with endemic treponemal infections such as yaws, (T. pertenue), pinta (T. carateum) or bejel (T. endemicum) [23]. The detection of these false positives clearly reveals the non specificity of the rapid test strips and the need for a specific confirmatory test for syphilis [24]. Routine screening for syphilitic infection during antenatal care is a standard practice in Nigeria. Consistently reported low incidence this practice may be reconsidered and screening and treatment of other more common infection is suggested to prevent the adverse effects of those infections.

Gonococcal infection was diagnosed in two patients only in this study. The incidence appears low considering the high prevalence of this infection in the general population. Though this is in accord with other studies in Nigeria (0.1\% in Jos [22] to $0.5 \%$ in Kano [25]).

Table 5. Occurrence of infection among the pregnant women by occupations.

\begin{tabular}{|c|c|c|c|c|c|c|c|c|c|c|}
\hline \multirow{2}{*}{ Occupation } & \multirow{2}{*}{$\begin{array}{l}\text { No. } \\
\text { Tested }\end{array}$} & \multirow{2}{*}{$\begin{array}{l}\text { No (\%) } \\
\text { Positive }\end{array}$} & \multicolumn{8}{|c|}{ No. (\%) Positive for pathogens } \\
\hline & & & $\mathrm{Ng}$ & Ca.alb & T.V & G.V & T.P & HBsAg & HIV & Ch.sp \\
\hline Unemployed & 89 & $59(66.3)$ & & $21(23.6)$ & $9(8.3)$ & $3(2.8)$ & $2(1.9)$ & $1(0.9)$ & $11(10.2)$ & $9(8.30)$ \\
\hline Students & 28 & $14(50.0)$ & 1 & $8(28.6)$ & $16(4.4)$ & $6(1.7)$ & $4(1.1)$ & $5(1.4)$ & $23(6.4)$ & $20(5.5)$ \\
\hline Business & 140 & $66(47.1)$ & & $35(25.0)$ & $4(4.3)$ & $3(3.3)$ & $1(1.1)$ & $2(2.2)$ & $4(4.3)$ & $6(6.5)$ \\
\hline Civil servants & 105 & 48 (45.7) & 0 & $26(24.8)$ & $29(2.5)$ & $12(2.1)$ & $7(1.2)$ & $8(1.4)$ & $38(6.8)$ & $35(6.2)$ \\
\hline $\begin{array}{l}\text { House wives } \\
\text { (Fulltime) }\end{array}$ & 200 & $63(31.5)$ & 0 & $31(15.5)$ & $3(1.5)$ & $2(1.0)$ & $1(0.5)$ & $1(0.5)$ & $14(7.0)$ & $11(5.5)$ \\
\hline Total & 562 & $250(44.5)$ & 2 & $121(21.5)$ & $29(5.2)$ & $12(2.1)$ & $7(1.2)$ & $8(1.4)$ & 38 (6.8) & 35 (6.2) \\
\hline
\end{tabular}

$\mathrm{Ng}$ = Neisseria gonorrhoeae; HBsAg = Hepatitis B surface antigen; Ca.sp = Candida albicans; HIV = Human Immunodeficiency Virus; T.V = Gardnerella vaginalis; Ch.sp = Chlamydia species; T.P = Treponema pallidum; - = Denotes that no pathogen was detected. 
This finding is unclear but could be attributable to the fact that male consort are often symptomatic male and therefore present for treatment early subsequent with contract tracing and in the woman. Also, abuse of broad spectrum antimicrobials which can easily be obtained over the counter of patent medicine dealers and pharmacy shops without authorized prescriptions could be a contributing factor. Our findings may be incidental arising from a pool of lightly infected population because of increase condom use and awareness of current incurable HIV pandemic in the world amongst the different age groups investigated, infection distribution was highest in the adolescence. The results of this survey is in agreement with generally observed fact that the incident of STDs by the number of cases treated each year is highest among the 15 - 24 years old [10,26,27]. Similarly, earlier data from studies by Aboyeyi \& Nwabuisi [20], Jombo et al., [22] Enabulele \& Kemajou [28], and Adekanle et al., [29] reported that those in the age group of 15 - 30 years were the most infected (100\%) by one STD or the other in their separate studies. The World Health Organization [3] concludes that this age group (15 - 30 years) is persons with the greatest sexual activity and that incidence decreases with age. Infections also appear to be commoner in the first trimester. This is important as detection and proper management at this early stage of pregnancy would reduce perinatal transmission.

Educational status, occupation, circumcision status, use of contraceptive methods, influence and level of perception/awareness of STDs, income levels of pregnant subjects studied were all significantly linked with infection occurrence and distribution $(\mathrm{P}<0.05)$. Meanwhile, marital status, length of union and religion of pregnant women were not significantly associated with infection occurrence $(P>0.05)$.

High STD infection rate among pregnant women are clear signs that ways to reach those at risk women must be developed and promoted for early recourse to health services, especially routine mandatory and early screening of all pregnant women for STDS. Proper treatment of all STDs like use of correct and effective medicines, contact tracing and treatment of sexual partners and education of the general populace should not be overlooked in our locality.

\section{REFERENCES}

[1] Gilson, R. and Mindel, A. (2001) Recent advances: Sexually transmitted infections. British Medical Journal, 322, 1160-1164. doi:10.1136/bmj.322.7295.1160

[2] World Health Organization (WHO) (2001) Global prevalence and incidence of selected curable sexually transmitted infections: Overview and estimates. Geneva. http://www.who.int/publishers/en.html
[3] World Health Organization (WHO) (2006) Global prevalence and incidence of STDs. Overview and estimates. Geneva. http://www.who.int/genomics/publishers/en/index/html

[4] Shafer, M. and Moscicki, A. (2006) Sexually transmitted infections, 1-8.

http://www.biomedexperts.comProfile.bme/...Mary-Ann Shafer

[5] Institute of Medicine (IOM) (1997) The Hidden epidemic: Confronting sexually transmitted diseases. National Academy Press, Washington DC.

http://www.nap.edu/openbook.php?recordId=5284

[6] Center for Disease Control \& Prevention (2000) Sexually transmitted disease surveillance. Division of STD Prevention, Health and Human Service, Atlanta, 112-134.

[7] World Health Organization (WHO) (2005) Guidelines for the treatment of sexually transmitted diseases. Morbidity Mortality Weekly Recommendation Report, 47, 1-118.

[8] World Health Organization (WHO) (1995) Global epidemiology of sexually transmitted diseases. Asian Journal of Andrology, 10, 110-114.

[9] Centre for Disease Control \& Prevention (2002) Sexually transmitted diseases guidelines. Morbidity \& Mortality Weekly Recommendation Report, 51, 1-78.

[10] Center for Disease Control \& Prevention (2006) Sexually transmitted diseases treatment guidelines. Morbidity \& Mortality Weekly Recommendation Report, 55. www.cdc/gov/std/treatment.

[11] UNAIDS (2003) Follow up to the 2001 United Nations General Assembly special session on HIVE/AIDS and sexually transmitted diseases. Progress Report on the Global Response to the HIV/AIDS \& STD Epidemic.

[12] Center for Disease Control (2008) National STD prevention conference. Confronting challenges, applying solutions. Division of STD prevention for HIVE/AIDS Viral Hepatitis, STD and TB prevention. CDC Press Release, 404, 639-899.

[13] Colombo, U.F., Bregozzo, T., Bizioli, B., Garlaschi, M.L., Varotto, E. and Mangnabosco, G. (1987) Screening for sexually transmitted diseases in sexually active adolescents. Annals of Obstetric and Gynaecology/Medical Perinatology, 108, 245-250.

[14] World Health Organization (WHO) (2001) WHO guidelines for sexually transmitted infections; prevalence study. WHO Project ICP RHR 001, Regional Office for SouthEast Asia, New Delhi.

[15] Stuart, R.D., Toahw, R.S. and Postula, T.M. (1954) Transport medium for neisseria gonorrhoeae. Ganadian Journal of Public Health, 45, 13-53.

[16] Thayer, J.D. and Martin, J.E. (1966) A selective medium for the cultivation of Neisseria gonorrhoeae. Public Health Report, 815, 559-562. doi:10.2307/4592771

[17] World Health Organization (WHO) (2005) Guidelines for the treatment of sexually transmitted diseases. Morbidity Mortality Weekly Recommendation Report, 47, 1-118.

[18] Federal Ministry of Health (FMH) (2005) Technical report on national HIV/syphilis sero-prevalence sentinel sur- 
vey among pregnant women attending antenatal clinics in Nigeria.

[19] Larsen, S.A., Sandra, A., et al., (1990) A manual of tests of syphilis. American Public Health Association, Washington DC, 1-192.

[20] Aboyeji, A.P. and Nwabuisi, C. (2003) Prevalence of sexually transmitted diseases among pregnant women in Ilorin, Nigeria. Journal of Obstetrics \& Gynaecology, 23, 637-639. doi:10.1080/01443610310001604411

[21] Oyelese, A.O., Onipede, A.O. and Aboderin, A.O. (2005) Sexually transmitted infections in Obafemi Awolowo University Teaching Hospital, Ile-Ife, Nigeria. A decade of clinic experience. African Journal of Clinical and Experimental Microbiology, 6, 64-68.

[22] Jombo, G.T.A., Egah, D.Z., Banwate, E.B. and Opajobi, S.O. (2006) High vaginal and endocervical swabs: A bacteriological study of 8433 samples in Jos, Nigeria. Journal of Medical Laboratory Science, 15, 41-46.

[23] Noris, S.J. (2003). Treponema and other human host-associated spirochetes. In: Murray, P.R., et al., Eds., Manual of Clinical Microbiology, 8th Edition, Amsterdam Society of Medicine Press, Amsterdam.
[24] Larsen, S.A. (1995) Laboratory diagnosis and interpretation of tests for syphilis. Clinical Microbiology Reviews, 130, 2353-2358.

[25] Nwokwsi, E.E., Azeez-Akande, O. and Dikkko, A.U. (2004) Pattern of sexually transmitted infections in a reference-clinic of Amino Kano Teaching Hospital, Kano. Highland Medical and Research Journal, 2, 55-60.

[26] Bustamante, M., Rodlescia, S.O., Connell, E., Guoyong, Z. and Fermin, L. (2006) Prevalence of sexually transmitted diseases in pregnant women: Miami Dade county, in Florida. EPI Monthly Report, 7, 12.

[27] Varkey, E.E. (2007) Medicine specialties; excepts from cervicities. Obstetrics and Gynaecology Infections Manual, 3, 232-238.

[28] Enabulele, I.O. and Kemajou, T.S. (2006) Prevalence of sexually transmitted infections in patients attending sexually transmitted disease (STD) Clinics in Benin City, Nigeria. Journal of Medical Laboratory Science, 15, 60.

[29] Adekanle, D.A., Adeyemi, A.S. and Odu O.O. (2008) Teenage and non-teenage pregnant women in south western Nigeria. A descriptive study. Calicut Medical Journal, 693, e5. 